\title{
Characterizing uranium surface speciation on Na-montmorillonite
}

\author{
R. M. TINNACHER ${ }^{1, *}$, M. MASSEY ${ }^{1}$, \\ A. BHATTACHARYYA ${ }^{1,2}$, S. GRANGEON ${ }^{3}$, \\ C. TOURNASSAT ${ }^{2,3}$
}

${ }^{1}$ California State University East Bay, Hayward, CA 94542

(*correspondance: Ruth.Tinnacher@csueastbay.edu)

${ }^{2}$ Lawrence Berkeley National Lab, Berkeley, CA 94720

${ }^{3}$ UMR 7327 Institut des Sciences de la Terre d'Orléans,

Université d'Orléans - CNRS/INSU - BRGM, Orléans

In engineered barrier systems (EBS) at future nuclear waste repositories, Na-montmorillonite is expected to limit contaminant mobility due to its low permeability and high sorption affinity for many radionuclides. A mechanistic understanding of radionuclide sorption reactions and their speciation on montmorillonite surfaces is needed in order to accurately predict contaminant transport based on surface complexation and reactive transport models.

In this study, we characterized uranium surface speciation on montmorillonite with the primary goal to examine the formation of U(VI)-carbonato surface complexes on Na-montmorillonite. This type of surface complex has been invoked in a number of previously-published U(VI)montmorillonite sorption models that do not specifically account for the "spill-over" effect, the influence of the electrostatic potential of basal surface sites on the potential of edge surface sites. However, our recently developed surface complexation model including the spill-over effect was able to predict $\mathrm{U}(\mathrm{VI})$ sorption onto Na-montmorillonite over a wide range of $\mathrm{pH}$ and $\mathrm{pCO}_{2}$ conditions without involving any $\mathrm{U}(\mathrm{VI})$-carbonato surface complexes. Surface speciation of $U$ is therefore a key question.

We have now characterized uranium surface speciation on montmorillonite by EXAFS spectroscopy over a range of $\mathrm{pH}$ conditions ( $\mathrm{pH} \mathrm{5,} 7$ and 8), total $\mathrm{U}$ and Ca concentrations, and in the presence and absence of atmospheric $\mathrm{CO}_{2}$. Uranium $L_{3}$-edge EXAFS spectra were surprisingly similar, even though chemical solution conditions had been varied. These preliminary results suggest that despite the fact that $\mathrm{U}(\mathrm{VI})$ solution speciation is substantially different under various chemical conditions, $U$ surface speciation on Na-montmorillonite may remain quite similar. These results support the current parametrization of our surface complexation model, which does not include any U-carbonato surface complexes.

This research is funded through DOE's Nuclear Energy University Program. 